\title{
Development and Validation of Bioanalytical HPLC Method For Estimation of Telmisartan In Rat Plasma: Application To Pharmacokinetic Studies
}

\author{
J aydeep M. Patel ${ }^{1}$, Anjali P. Dhingani ${ }^{2}$, Kevin C. Garala ${ }^{2}$, Mihir K. Raval ${ }^{1}$ \\ and Navin R. Sheth ${ }^{1}$ \\ ${ }^{1}$ Department of Pharmaceutical Sciences, Saurashtra University, Rajkot-360005, Gujarat, India. \\ ${ }^{2}$ Atmiya Institute of Pharmacy, Kalawad Road, Rajkot-360005, Gujarat, India.
}

\begin{abstract}
A simple, specific, sensitive and rapid reversed phase high performance liquid chromatographic (HPLC) method has been developed and validated for the determination of telmisartan in small volumes of rat plasma. Biological sample preparation involving simple extraction with organic solvent, followed by dilution with mobile phase was adopted to eliminate any chromatographic solvent effects. The method was proven to be linear over a plasma concentration range of 10 to $1000 \mathrm{ng} / \mathrm{mL}$ with a mean correlation coefficient of 0.9942 . The limit of detection and the limit of quantification of the newly developed method were determined to be $1 \mathrm{ng} / \mathrm{mL}$ and 10 $\mathrm{ng} / \mathrm{mL}$, respectively. The method was successfully applied to assess pharmacokinetic parameters of telmisartan in Wister rats following a single oral dose $(1.8 \mathrm{mg} / \mathrm{kg}$, b.w.). The developed method was established as a rapid analytical tool in a pharmacokinetic study as it required short retention time, high precision, sensitivity and small volumes of plasma for analysis.
\end{abstract}

Keywords: Bioanalytical method, Telmisartan, HPLC, Pharmacokinetics, Rat plasma

\section{INTRODUCTION}

Telmisartan (TLM) is 2-[4-[[4-methyl-6-(1methylbenzimidazol-2-yl)-2 propylbenzimidazol-1yl]-methyl]phenyl]benzoic acid (Figure 1), is a synthetic analogue of angiotensin II receptor blocker, used for the treatment of hypertension. TLM is a poorly water-soluble drug which displays a dissolution rate-limited absorption pattern in humans and animals. Hence, it can be used as a model drug to assess the influence of various physicochemical, physiological, and dosage form factors on the absorption kinetics and bioavailability of hydrophobic drugs. ${ }^{1-6}$

A variety of methods have been developed for determination of TLM individually or with combination with some other antihypertensive agents in biological samples. ${ }^{7-9}$ This includes, HPLC coupled with mass spectrometric (HPLC-MS) and

Correspondence to: Mr. Jaydeep M. Patel, Phone: +919624801807, Fax: +912812585083 spectrofluorimetric detection. ${ }^{10,11}$ In general, spectrofluorimetric method lack sensitivity and cannot distinguish degradation products from the parent compound. Although HPLC-MS methods provide excellent sensitivity, they are not available in all laboratories because of their special requirements and economic considerations. Moreover, spectrofluorimetric method utilized either a column switching system or an expensive solid phase extraction cartridges. With respect to these, all reported methods for TLM have various limitations: time-consuming sample clean-up, laborious extraction steps and long chromatographic elution time. Moreover, all these methods have utilized human plasma for the study. Thus, the present study has been undertaken to develop and validate a simple, sensitive, accurate, precise and reproducible bioanalytical HPLC method for estimation of TLM in rat plasma. 


\section{MATERIALS AND METHODS}

TLM was gifted form Torrent Research Center, Gandhinagar, India. Acetonitrile (HPLC grade), methanol (HPLC grade) and potassium dihydrogen phosphate were purchased from Merck Chemicals, Mumbai, India. Double deionized water was utilized for entire study.

Animals. Male Wister rats with an average weight of $200 \pm 20 \mathrm{gm}$ and age $\sim 10$ weeks (on the day of study) were procured in order to investigate pharmacokinetic behavior of TLM. The study was approved by Institutional Ethics Committee of Department of Pharmaceutical Sciences, Saurashtra University, Rajkot, Gujarat, India (CPCSEA No: SU/DPS/IAEC/1003, Dated: 11/02/2010) and the guidelines were followed throughout the study. All the rats were acclimatized to a temperature (20 \pm $\left.2^{\circ} \mathrm{C}\right)$ and relative humidity $(45 \pm 15 \%)$, with a $12 \mathrm{~h}$ light/dark cycle over a period of 5 days prior to administration of drug. During this acclimatization period, the animals were carefully observed to ensure their good health and suitability for inclusion in the study. For all rats a standard laboratory diet (PranavAgromart Ltd, Baroda, India) and domestic mains tap water were available ad libitum. The animals were disconnected from diet at least $12 \mathrm{~h}$ before dosing. During study periods, rats were housed singly in polypropylene and stainless steel cages. ${ }^{12,13}$

A High Performance Liquid Chromatograph (HPLC) equipped with Shimadzu LC SOLUTION was employed for the present investigation. The system consisted of Shimadzu UFLC 20-AD as binary solvent delivery system, Shimadzu 7D Rheodyne injector as loop injector and Photo Diode Array (PDA) detector as a source of detection.

Chromatographic conditions. A combination of methanol and acetonitrile (70:30 \%v/v) was selected as mobile phase. Samples were separated using Phenomenex Luna ${ }^{\circledR} \mathrm{C}_{8}$ column with a pore size $100 \AA$, length $300 \mathrm{~mm}$ and internal diameter (i.d.) 4.6 $\mathrm{mm}$. The mobile phase was injected to the system using binary pumping mode at a flow rate of 1 $\mathrm{ml} / \mathrm{min}$. For all samples, injection volume and run time were fixed as $20 \mu \mathrm{L}$ and $10 \mathrm{~min}$, respectively.
Preparation of mobile phase. For preparing a mobile phase, HPLC grade methanol and acetonitrile were filtered through a $0.2 \mu \mathrm{m}$ membrane filter and subjected to degassing in an ultrasonic bath (Frontline FS-4, Mumbai, India) for a period of 15 $\min$.

Preparation of standard solutions. A primary stock solution $(1 \mathrm{mg} / \mathrm{ml})$ was prepared by dissolving $10 \mathrm{mg}$ of TLM in $10 \mathrm{ml}$ of HPLC grade methanol. The stock solution was suitably diluted with HPLC grade methanol to obtain working range of standard solutions. The working standard solutions were prepared in duplicates, out of which one set was used to prepare calibration curve and the other was used to generate quality control (QC) samples. Plasma used in the study was isolated from rat's blood by centrifugation at $10000 \mathrm{rpm}$ for a period of $15 \mathrm{~min}$ at $4^{\circ} \mathrm{C}$, using a centrifuge (Remi Laboratory Instruments, Mumbai, India). The calibration curve samples were prepared by spiking $500 \mu \mathrm{l}$ of drug free rat plasma with $100 \mu \mathrm{L}$ of previously diluted working standard solution in order to obtain final concentrations of $10,25,50,75,100,250,500,750$ and $1000 \mathrm{ng} / \mathrm{ml}$. The QC samples [30 ng/ml (LQC), $250 \mathrm{ng} / \mathrm{ml}$ (MQC) and $900 \mathrm{ng} / \mathrm{ml}$ (HQC)] were prepared by spiking second set of working solutions to the pooled blank plasma. All samples were stored at refrigerated cold conditions $\left(2-8^{\circ} \mathrm{C}\right)$ and equilibrated to room temperature prior to use. ${ }^{14,15}$

Sample preparation. Prior to sample analysis, $100 \mu \mathrm{L}$ of each solution was extracted using $300 \mu \mathrm{L}$ of diethylether: dichloromethane $(60: 40 \% \mathrm{v} / \mathrm{v})$ for protein precipitation. Further, each of the mixtures was vortexed for a period of $5 \mathrm{~min}$ in a vortexe (GeNei, Bangalore, India) mixer with subsequent centrifugation at $10000 \mathrm{rpm}$, for a period of $10 \mathrm{~min}$ at $4^{\circ} \mathrm{C}$ using a centrifuge. For each sample, an aliquot of a supernatant was isolated and subjected to dryness. The residue was reconstituted in $100 \mu \mathrm{L}$ of mobile phase and subsequently centrifuged at $10000 \mathrm{rpm}$ for $10 \mathrm{~min}$ at $4^{\circ} \mathrm{C}$ in a centrifuge. The supernatant was finally collected and directly injected into the HPLC system. This procedure was followed for all samples of calibration curve and QC. ${ }^{14,15}$ 
Construction of calibration curves. The values of peak areas were plotted against their respective concentrations in order to construct the calibration curve for TLM. Linear regression analysis was performed for each set of data using Microsoft Excel $^{\circledR}$ version 2010 (Microsoft Corporation, Washington, USA).

\section{Validation Parameters}

Linearity and range. The linearity and range of calibration curve was evaluated with nine calibration standards containing different concentrations of respective drug $(10,25,50,75,100,250,500,750$ and $1000 \mathrm{ng} / \mathrm{ml}$ ). The study was repeated in triplicates to confirm reproducibility of results. The concentrations of the test samples were backcalculated using linear regression analysis. ${ }^{14,15}$

Selectivity. Selectivity of developed method was assessed by comparing chromatograms of three different batches of blank plasma obtained from three individual rats with those of corresponding standard plasma samples. ${ }^{14,15}$

Accuracy and precision. Intra-day precision and accuracy of the developed method was determined by analyzing six replicates of QC samples at three concentrations in a single sequence. Similarly, for inter-day precision and accuracy; six replicates QC samples at three concentrations were analyzed on three consecutive days. The accuracy of method was determined by calculating $\%$ relative error (\%RE) whereas the precision was determined by calculating $\%$ relative standard deviation (\%RSD). ${ }^{14,15}$

Robustness. The robustness of developed method was studied by evaluating the effect of small but deliberate variations in chromatographic conditions. The parameters studied were flow rate and mobile phase composition. ${ }^{14,15}$

Recovery (extraction efficiency). To investigate extraction efficiency of developed method, a set of samples $(n=6)$ at each QC level were prepared by spiking drug into plasma samples and processed further (pre-extraction). Similarly, a second set of plasma samples were processed first and spiked postextraction at each QC levels. Extraction recovery for each analyte was determined by calculating the ratios of peak areas of the pre-extraction samples to those of the samples of post-extraction. ${ }^{14,15}$

Limits of detection (LOD) and limit of quantitation (LOQ). LOD and LOQ of the developed method were estimated on the basis of standard deviation and slope of the calibration curve as $3.3 \delta / \mathrm{m}$ and $10 \delta / \mathrm{m}$, respectively. Here, $\delta$ was the regression standard deviation of intercept and $m$ was the slope of calibration curve. ${ }^{14,15}$

Pharmacokinetic studies. The applicability of the developed HPLC method for TLM in rat plasma was demonstrated by the results obtained from pharmacokinetic studies conducted on male wister rats $(n=12)$. Each rat was treated with oral dispersing of TLM at a dose of $1.8 \mathrm{mg} / \mathrm{kg}$ in a single dose by curved gastric gavage tubes directly into the stomach. ${ }^{16}$ The dose volume for all administration was maintained at $5 \mathrm{ml} / \mathrm{kg} .^{12,13}$ Serial blood samples $(500 \mu \mathrm{L})$ were collected from retro-orbital venous plexus with hematocrit over a period $120 \mathrm{~h}$ (five biological half-life). Rats were further divided into two subgroup $(\mathrm{n}=6)$ for convenient blood sampling over entire study periods as recommended by the experts of IAEC (Institutional Animal Ethics Committee). Blood samples from each group were collected at predetermined time intervals alternatively from each subgroup into heparinized plastic tubes. All these samples of whole blood were kept in refrigerated cold conditions $\left(2-8^{\circ} \mathrm{C}\right)$ until separation of plasma. Each sample was processed further by the method as mentioned under sample preparation and subjected to HPLC analysis for the estimation of drug content by a previously validated bioanalytical method. The pharmacokinetic calculations were performed on the basis of plasma concentration-time data using Kinetica ${ }^{\circledR}$ version 5.1 (Thermo Scientific, USA) pharmacokinetics and pharmacodynamics software. ${ }^{17-19}$

Animal rights. The experimental protocol was approved by the Institutional Animal Ethics Committee of the Saurashtra University, Rajkot, Gujarat and the care and handling of the animals 
were in accordance with the National institutes of health guidelines.

\section{RESULTS AND DISCUSSION}

Proper analysis is an important component in formulation and development of any drug molecule. A suitable and validated method has to be available for the analysis of drug(s) in bulk, drug delivery systems, in vitro and in vivo. If such suitable method for specific need is not available then it becomes essential to develop a simple, sensitive, accurate, precise, reproducible method for the estimation of drug samples. The present investigation was aimed to develop and validate bioanalytical HPLC method for estimation of TLM in rat plasma. ${ }^{14,15,20-22}$

Selection of chromatographic conditions. The chromatographic conditions were selected on the basis of backpressure, peak resolutions, peak shapes and day-to-day reproducibility of the retention time (Table 1). For selecting a mobile phase initial trial was taken using methanol and potassium dihydrogen phosphate buffer ( $\mathrm{pH} 3.5)$ in various phase ratios but the peaks were not of a good shape. Utilization of acetonitrile in place of phosphate buffer improved the peak shapes and hence, 70:30 of methanolacetonitrile was selected as mobile phase for further trials (Figure 2).

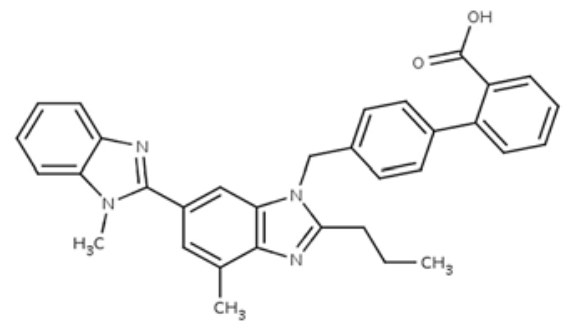

Figure 1. Structure of telmisartan

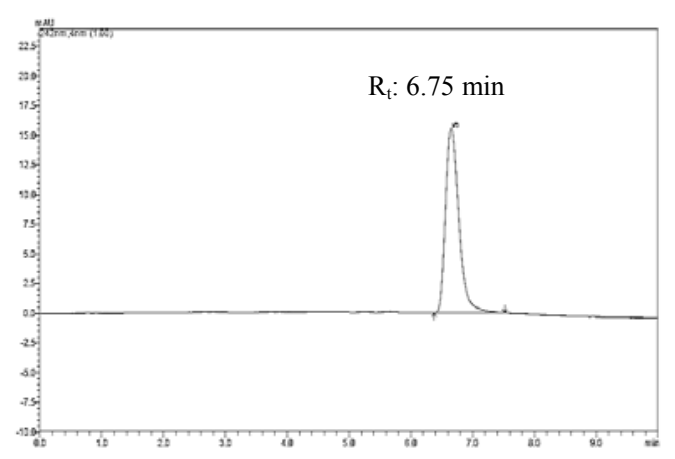

Figure 2. HPLC Chromatogram of TLM.

\section{Validation}

Linearity and range. The mean regression equation of three standard curves for TLM was $y=525.83 x+27330$, where y presented peak area of drug and $\mathrm{x}$ was the plasma concentration of drug. The precisions (\% CV) of the slope and intercept were less than $2 \%$ for both drugs which indicated minimum variations. ${ }^{14,15}$

The calibration curve was linear over the studied concentration range $(10-1000 \mathrm{ng} / \mathrm{ml})$ with a mean correlation coefficient more than 0.99 (Table 2 and Figure 3).

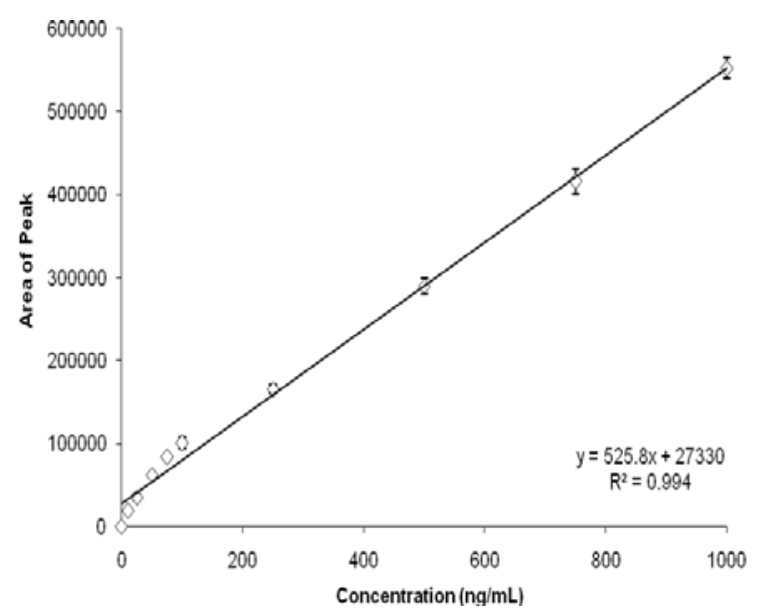

Figure 3. Calibration curve for plasma samples of TLM.

Table 1. Chromatographic conditions for bioanalytical method development.

\begin{tabular}{ll}
\hline Chromatographic Conditions \\
\hline Pumping mode & Binary \\
Mobile phase & Methanol and acetonitrile $(70: 30 \% \mathrm{v} / \mathrm{v})$ \\
Column & Phenomenex Luna ${ }^{\circledR} \mathrm{C}_{8}$ \\
& Pore size $-100 \AA$, Length $-300 \mathrm{~mm}$, i.d. \\
& $-4.6 \mathrm{~mm}$ \\
$\lambda$ Scanning range & $190-800 \mathrm{~nm}$ \\
Flow rate & $1 \mathrm{ml} / \mathrm{min}$ \\
Injection volume & $20 \mu 1$ \\
Run time & $10 \mathrm{~min}$ \\
\hline
\end{tabular}

Selectivity. It is the ability of an analytical method to differentiate and quantify analyte in the presence of other components of the samples. Each blank sample was evaluated for interference with respective drug. ${ }^{14,15}$ The results revealed that the analyte (TLM) was well separated from co-extracted material under the adopted chromatographic conditions. The retention time $\left(\mathrm{R}_{\mathrm{t}}\right)$ was $6.75 \mathrm{~min}$ 
(Figure 2). In addition to this, the chromatogram of extracted plasma samples did not show any coeluting interference peak with the analyte which suggested good degree of selectivity for the developed method.

Table 2. Calibration curves for plasma samples of drugs.

\begin{tabular}{lc}
\hline Concentration $(\mathrm{ng} / \mathrm{ml})$ & $\begin{array}{c}\text { Peak Area }[\text { mean } \pm \\
\text { SD }(\mathrm{n}=3)]\end{array}$ \\
\hline 10 & $19216.68 \pm 1626.30$ \\
25 & $35219.65 \pm 3683.53$ \\
50 & $62383.76 \pm 3110.53$ \\
75 & $83856.36 \pm 2671.75$ \\
100 & $100402.78 \pm 1175.49$ \\
250 & $165781.02 \pm 5046.08$ \\
500 & $289609.65 \pm 9404.97$ \\
750 & $415955.37 \pm 15397.35$ \\
1000 & $552563.32 \pm 12456.82$ \\
\hline
\end{tabular}

Accuracy and precision. The accuracy of an analytical method describes the closeness of test results to the true concentration of analytes whereas the precision is a measure of degree of reproducibility of analytical method. ${ }^{14,15}$ The results of intra-day and inter-day precisions are summarized in Table 3 which revealed that developed method was accurate and precise for quantification of TLM in plasma samples.

Robustness. The low values of \%RSD for each of drug proposed that during all deliberate variations, assay value of test preparation (MQC) was not affected and it was in accordance with that of actual (Table 4). Hence, the newly developed analytical method was considered to be robust. ${ }^{14,15}$

Recovery (Extraction efficiency). The high value of recoveries for TLM specified that insignificant amounts of drug was lost during plasma protein precipitation step. ${ }^{14,15}$ Lower values of \%RSD advocated high degree of extraction efficiency of developed method (Table 5).

Table 3. Intra and inter-day accuracy and precision of bioanalytical method.

\begin{tabular}{lccccc}
\hline \multirow{2}{*}{$\begin{array}{l}\text { Nominal } \\
\text { Conc. }\end{array}$} & \multirow{2}{*}{$\begin{array}{c}\text { Mean Area } \\
\pm \mathrm{SD}(\mathrm{n}=6)\end{array}$} & $\begin{array}{c}\text { \%ntra- } \\
\text { day }\end{array}$ & $\begin{array}{c}\text { Inter } \\
\text {-day }\end{array}$ & $\begin{array}{c}\text { Intr- } \\
\text { aday }\end{array}$ & $\begin{array}{c}\text { Inter } \\
\text {-day }\end{array}$ \\
\hline LQC & $31.02 \pm 0.98$ & 3.6 & 4.8 & 6.5 & 4.2 \\
MQC & $247.90 \pm 3.56$ & 2.3 & 3.5 & 4.1 & 3.6 \\
HQC & $910.56 \pm 6.23$ & 1.4 & 2.4 & 3.3 & 2.9 \\
\hline
\end{tabular}

Table 4. Robustness study of bioanalytical method.

\begin{tabular}{lccc}
\hline Flow Rate $(\mathrm{ml} / \mathrm{min})$ & 0.8 & 1.0 & 1.2 \\
\hline Mean $(\mathrm{n}=3)$ & 165221 & 165781 & 165890 \\
\%RSD & 1.21 & 1.42 & 2.85 \\
\hline Mobile Phase Ratio (\%v/v) & $\mathbf{6 5 : 3 5}$ & $\mathbf{7 0 : 3 0}$ & $\mathbf{7 5 : 2 5}$ \\
\hline Mean $(\mathrm{n}=3)$ & 165512 & 165781 & 165490 \\
\%RSD & 2.32 & 1.90 & 4.39 \\
\hline
\end{tabular}

Table 5. Recovery study of bioanalytical method.

\begin{tabular}{lcc}
\hline Nominal Conc. & \% Recovery & \% RSD \\
\hline LQC & 95.8 & 3.59 \\
MQC & 98.0 & 2.36 \\
HQC & 93.2 & 5.24 \\
\hline
\end{tabular}

Limits of detection (LOD) and quantitation (LOQ). The LOD and LOQ were observed as 1 $\mathrm{ng} / \mathrm{mL}$ and $10 \mathrm{ng} / \mathrm{ml}$, respectively. These low values were indicative of high sensitivity of developed method.

Pharmacokinetic study. The proposed HPLC method was successfully applied to monitor quantitatively the time course of plasma TLM concentrations after oral administration of a single $1.8 \mathrm{mg} / \mathrm{kg}$ b.w. dose to adult male Wister rats. The mean plasma drug concentration-time profile observed in these pharmacokinetics studies is shown in Figure 4. The values of all major pharmacokinetic parameters like maximum plasma concentration $\left(\mathrm{C}_{\max }\right)$, time required for maximum plasma concentration $\left(\mathrm{T}_{\max }\right)$, area under curve $\left(\mathrm{AUC}_{0-\infty}\right)$, area under first moment curve $\left(\mathrm{AUMC}_{0-\infty}\right)$, terminal halflife $\left(t_{1 / 2)}\right.$, mean residence time (MRT) and clearance have been summarized in Table 7 .

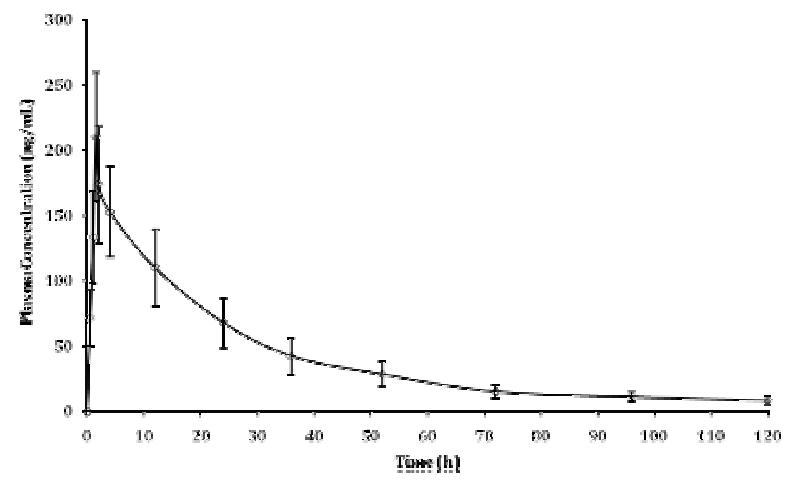

Figure 4. In vivo pharmacokinetic profiles of TLM, Error bar represents $\mathrm{SD}(\mathrm{n}=6)$. 
Table 6. Summary of validation parameters of bioanalytical method.

\begin{tabular}{lc}
\hline Parameters & Results \\
\hline Linearity Range $(\mathrm{ng} / \mathrm{ml})$ & $10-1000$ \\
Correlation Coefficient $\left(\mathrm{r}^{2}\right)$ & 0.9942 \\
Slope & 525.83 \\
Intercept & 27330 \\
Limit of Detection (LOD) $(\mathrm{ng} / \mathrm{ml})$ & 1 \\
Limit of Quantification $(\mathrm{LOQ})(\mathrm{ng} / \mathrm{ml})$ & 10 \\
Retention Time $\left(\mathrm{R}_{\mathrm{t}}\right)(\mathrm{min})$ & 6.75 \\
\hline
\end{tabular}

Table 7. Results of in vivo pharmacokinetic study of TLM.

\begin{tabular}{lc}
\hline Parameters & Mean $\pm \mathrm{SD}(\mathrm{n}=6)$ \\
\hline $\mathrm{C}_{\max }(\mathrm{ng} / \mathrm{ml})$ & $505.35 \pm 112.65$ \\
$\mathrm{~T}_{\max }(\mathrm{h})$ & $1.24 \pm 0.18$ \\
$\mathrm{AUC}_{0-\infty}(\mathrm{ng} \cdot \mathrm{h} / \mathrm{ml})$ & $11420.23 \pm 2028.54$ \\
$\mathrm{AUMC}_{0-\infty}\left(\mathrm{ng} \cdot \mathrm{h}^{2} / \mathrm{ml}\right)$ & $384519.09 \pm 8532.58$ \\
$\mathrm{t}_{1 / 2}$ & $22.29 \pm 1.43$ \\
MRT $(\mathrm{h})$ & $33.67 \pm 2.24$ \\
Clearance $(\mathrm{ml} / \mathrm{h})$ & $0.03152 \pm 0.0014$ \\
\hline
\end{tabular}

\section{CONCLUSIONS}

A simple, rapid, specific, sensitive and reproducible HPLC method has been developed and validated for the quantitative determination of TLM in small volumes of rat plasma. The method is suitable for studying the pharmacokinetic parameters of TLM in rat model. This method can also be used for quality control tests of TLM in bulk and pharmaceutical dosage forms.

\section{ACKNOWLEDGEMENT}

The authors are very thankful to Torrent Research Center, Gandhinagar, India for providing gift sample of Telmisartan.

\section{REFERENCES}

1. http://www.drugs.com/cdi/telmisartan.html (Accessed on 21/07/2012).

2. http://www.rxlist.com/cgi/generic/telmisartan.htm (Accessed on $21 / 07 / 2012$ )

3. Ruilope, LM. 2011. Telmisartan for the management of patients at high cardiovascular risk. Cur. Med. Res. Opin. 27, 1673-1682.

4. Moffat, A.C., Osselton, M.D. and Widdop, B. 2004. Clarkel's Analysis of Drugs and Poisons. $3^{\text {rd }}$ ed. K. M. Varghere Company, Mumbai.
5. Nakatani, M., Takeshi, S., Ohki, T. and Toyoshima. K. 2004. Solid telmisartan pharmaceutical formulations. US Patent 0110813A1.

6. Sweetman, S.C. 2005. Martindale - The Complete Drug Reference. Pharmaceutical Press, London.

7. Rane, V.P., Sangshetti, J.N. and Shinde, D.B. 2008. Simultaneous high-performance liquid chromatographic determination of telmisartan and hydrochlorothiazide in pharmaceutical preparation. J. Chromatogr. Sci. 46, 887-891.

8. Lara, F.T., Maha, F.T., Mamoun, I.A., Manal, H.K. and Adi, I.A. 2010. Simultaneous determination of irbesartan and hydrochlorothiazide in human plasma using HPLC coupled with tandem mass spectrometry: Application to bioequivalence studies. J. Pharm. Biomed. Anal. 51, 985990.

9. Vasu, B.R., Jaswanth, K.I., Nageswara, R.P., Vudagandla, S. and Venkateswarlu, P. 2012. Simultaneous determination of telmisartan and amlodipine in human plasma by LC-MS/MS and its application in a human pharmacokinetic study. $J$. Pharm. Anal. (in press).

10. Christel, H., Liane, G., Ulrich, K. and Uwe, K. 2006. Determination of telmisartan in human blood plasma Part II: Liquid chromatography-tandem mass spectrometry method development, comparison to immunoassay and pharmacokinetic study. Anal. Chimica. Acta 560, 41-49.

11. Shah, R.P. and Singh, S. 2010. Identification and characterization of a photolytic degradation product of telmisartan using LC-MS/TOF, LC-MSn, LC-NMR and online H/D exchange mass studies. J. Pharm. Biomed. Anal. 53, 755-761.

12. He, Z., Yunyun, J., Jun, W., Tingting, Z., Guorong, F. and Yutian, W. 2009. Rapid determination of telmisartan in human plasma by HPLC using a monolithic column with fluorescence detection and its application to a bioequivalence study. J. Chromato. gr. B. 877, 3729-3733.

13. Balakrishnan, P., Lee, B., Hoon, D.O., Kim, J.O., Hong, M.J., Jee, J., Kim, J.A., Yoo, B.K., Wooa, J.S., Yong, C.S. and Choi, H. 2009. Enhanced oral bioavailability of dexibuprofen by a novel solid self-emulsifying drug delivery system (SEDDS). Eur. J. Pharm. Biopharm. 72, 539-45.

14. Patel, D. and Sawant, K.K. 2007. Oral bioavailability enhancement of acyclovir by self-microemulsifying drug delivery systems (SMEDDS). Drug Dev. Ind. Pharm. 33, 1318-1326.

15. ICH Harmonized tripartite guideline validation of analytical procedures: text and methodology Q2 (R1), Parent Guidelines dated October 27, 1994.

16. FDA guidance for industry: Bioanalytical method validation. US Department of Health and Human Services, Food and Drug Administration, Center for Drug Evaluation and Research, 2001.

17. Ghosh, M.N. 2008. Fundamentals of experimental pharmacology. $3^{\text {rd }}$ ed. SK Ghosh \& Others, Calcutta, India. 
18. Brahmankar, D.M. and Jaiswal, B.S. 1987. Biopharmaceutics and Pharmacokinetics: A treatise. $1^{\text {st }}$ ed. VallabhPrakashan, New Delhi, India.

19. Nepal, P.R., Han, H. and Choi, H. 2010. Preparation and in vitro-in vivo evaluation of Witepsol ${ }^{\circledR}$ H35 based selfnanoemulsifying drug delivery systems (SNEDDS) of coenzyme Q10. Eur. J. Pharm. 39, 224-232.

20. Minghui, S., Luqin, S., Xuezhen, Z., Zhaoze, F., Yiming, M., Rui, Z. and Xiangliang, Y. 2011. The influence of cosolvents on the stability and bioavailability of rapamycin formulated in self-microemulsifying drug delivery systems. Drug Dev. Ind. Pharm. 37, 986-994.
21. British Pharmacopoeia (BP), International edition. HMSO Publication: London, 2011.

22. Indian Pharmacopoeia (IP). The Controller of Publication: New Delhi, 2010.

23. United States Pharmacopeia and National Formulary. 2007. USP 30-NF 25, The United States Pharmacopeial Convention, Rockville, MD. 